\title{
APLIKASI TEKNOLOGI FINISHING KAYU BAGI KELOMPOK PERTUKANGAN DESA PAGERHARJO, KECAMATAN SAMIGALUH KABUPATEN KULON PROGO, D.I. YOGYAKARTA
}

\author{
Agus Ngadianto' ${ }^{1}$, Silvi Nur Oktalina ${ }^{1}$, Eko Prasetyo $^{1}$ dan Agung Budi Wibowo² \\ ${ }^{1}$ Program Studi Pengelolaan Hutan, Departemen Teknologi Hayati dan Veteriner \\ Sekolah Vokasi, Universitas Gadjah Mada
}

${ }^{2}$ Sekolah Vokasi Universitas Gadjah Mada

Email: agus.ng@ugm.ac.id

\begin{abstract}
ABSTRAK
Kelompok pertukangan Muda Taruna Makmur dan Mitra Mandiri merupakan kelompok usaha mikro dibidang produk perkayuan dan mebel yang berlokasi di Desa Pagerharjo Kecamatan Samigaluh, Kabupaten Kulon Progo, D.I. Yogyakarta. Kelompok pertukangan ini beranggotakan pemuda-pemuda dalam satu desa. Mengingat potensi kayu dari hutan rakyat di Desa Pagerharjo yang sangat besar, maka sangat potensial sekali untuk dibuat usaha pembuatan produk mebel serta kerajinan. Permasalahan yang dialami oleh kelompok mitra adalah rendahnya kemampuan dalam membuat produk perkayuan sampai tahap finishing, kurangnya pemanfaatan teknologi informasi sebagai sarana pemasaran, minimnya kemampuan dalam membuat inovasi dan desain produk serta kurangnya keahlian dalam teknologi finishing kayu. Selama ini, produk perkayuan yang dihasilkan adalah berupa produk mebel setengah jadi seperti meja, kursi dan lemari yang dijual ke industri mebel kayu yang lebih besar atau dijual ke konsumen secara langsung. Tujuan program ini adalah untuk meningkatkan kapasitas kelompok pertukangan di Desa Pagerharjo dalam teknologi finishing kayu, manajemen pemasaran serta membuat inovasi desain produk. Solusi yang ditawarkan dalam program ini meliputi: pelatihan teknologi finishing produk perkayuan atau mebel, peningkatan kemampuan dalam desain dan inovasi produk serta pelatihan penggunaan teknologi informasi sebagai sarana pemasaran.
\end{abstract}

Kata kunci: Kelompok pertukangan, mebel, produk kayu, teknologi informasi, teknologi finishing

\section{ABSTRACT}

The carpentry groups of Muda Taruna Makmur and Mitra Mandiri are micro business groups in the field of wood products and furniture located in Pagerharjo Village, Samigaluh District, Kulon Progo Regency, D.I. Yogyakarta. This carpentry group consists of young people in one village. Given the enormous potential of timber from community forests in 
Pagerharjo Village, it is very potential to create a business for making furniture and handicraft products. The problems that have by this groups are the low ability to make wood products until the finishing stage, lack of utilization of information technology as a system of marketing, lack of ability to make innovations and product design and lack of expertise in wood finishing technology. So far, the wood products produced are in the form of semifinished furniture products such as tables, chairs and cabinets that are sold to the larger wood furniture industry or sold directly to consumers. The aim of this program is to increase the capacity of carpentry groups in Pagerharjo Village in wood finishing technology, marketing management and to make product design innovations. The solutions offered in this program include: training in wood finishing technology, increased capability in product design and innovation and training in the use of information technology as a marketing system.

Keywords: Carpentry groups, furniture, wood products, information technology, finishing technology

\section{PENDAHULUAN}

Desa Pagerharjo merupakan salah satu desa yang berada di Kecamatan Samigaluh Kabupaten Kulon Progo. Sebagian besar wilayah Desa Pagerharjo merupakan zona pegunungan yaitu sekitar $1.037 \mathrm{Ha}$ dan sisanya merupakan zona datar. Sehingga, sebagian besar wilayah Desa Pagerharjo merupakan daerah pegunungan karena berada pada ketinggian 600 - 700 mdpl (Pemerintah Desa Pagerharjo, 2016). Desa Pagerharjo memiliki luas daerah sebesar 1.140,52 Ha atau 16,46\% dari total luas wilayah Kecamatan Samigaluh. Dari 1.140,52 ha luas keseluruhan, daerah Desa Pagerharjo dibagi menjadi lima daerah, yaitu : tanah sawah (118,68 ha), tanah kering (550,74 ha), bangunan $(329,26$ ha), hutan rakyat $(101,85$ ha), dan lainnya $(33,99)$. Berdasarkan data tersebut, sebesar $71,13 \%$ merupakan lahan terbuka seperti persawahan dan areal hutan rakyat (BPS Kabupaten Kulon Progo, 2016). Luasan hutan rakyat yang demikian besar, tentunya akan memberikan potensi hasil berupa kayu yang besar pula. Potensi kayu tersebut akan bertambah besar bila ditambah dari potensi kayu hutan rakyat yang berasal dari desa sekitarnya. Mengingat potensi kayu dari hutan rakyat di desa Pagerharjo yang sangat besar, maka hal ini mendorong sebagian masyarakat Desa Pagerharjo untuk membentuk suatu kelompok usaha mikro dibidang pertukangan dan pengrajin kayu. 
Pada desa Pagerharjo terdapat 2 kelompok pertukangan yang sebagian besar anggotanya adalah para pemuda desa. Kedua kelompok pertukangan ini adalah kelompok pertukangan Muda Taruna Makmur dan kelompok pertukangan Mitra Mandiri. Kelompok pertukangan tersebut selama ini hanya memproduksi produk perkayuan berupa produk mebel setengah jadi atau produk mebel tanpa pelapisan akhir atau finishing seperti meja, kursi dan lemari dan lain-lain. Selain itu, produk setengah jadi ini kebanyakan hanya dijual ke industri mebel kayu yang lebih besar untuk dapat diolah lebih lanjut proses finishingnya dan hanya sedikit saja yang dijual ke konsumen secara langsung. Hal ini dilakukan oleh mitra karena kurangnya ketrampilan dalam teknik finishing kayu ataupun pengerjaan akhir produk kayu selain itu kurang bervariasinya desain produk kayu yang dibuat. Akibat dari hal tersebut, harga jual produk mebel tanpa pelapisan akhir atau finishing yang dihasilkan lebih kecil dibandingkan harga produk mebel dengan finishing yang dijual dipasaran dengan perbedaan harga dapat mencapai $\pm 40 \%$. Permasalahan lain yang dimiliki oleh kelompok pertukangan desa Pagerharjo adalah mengenai strategi pemasaran yang masih kurang dilihat dari ketidakkonsistenan dalam memproduksi produk mebel karena selama ini hanya berdasarkan permintaan dan pesanan dari pembeli saja.

Mengingat kondisi pasar poduk kayu atau mebel kayu yang penuh dengan persaingan antar pengrajin, maka kelompok pertukangan desa Pagerharjo berkeinginan untuk mengembangkan produknya yang berbasis pada model desain yang inovatif dan perlakuan finishing yang dapat menarik minat konsumen terutama di Yogyakarta yang terkenal dengan tingkat seni dan kerajinannya. Untuk mewujudkan hal tersebut maka dirancang suatu program yang dimaksudkan untuk memberikan solusi dari permsalahan yang dimiliki oleh kedua kelompok pertukangan di desa Pagerharjo Kec. Samigaluh Kab. Kulon Progo. Solusi yang ditawarkan dalam program tersebut adalah berupa pelatihan teknologi finishing kayu yang didalamnya mencakup pengenalan teknik-teknik finishing produk perkayuan atau mebel, peningkatan kemampuan SDM dalam desain dan inovasi produk serta penggunaan teknologi informasi sebagai sarana pemasaran produk kayu dan mebel. Manfaat kegiatan ini adalah untuk memberi bekal kepada kelompok pertukangan kayu di Desa Pagerharjo, Kecamatan Samigaluh, Kabupaten Kulon Progo, D.I. Yogyakarta agar dapat menguasai 
teknik-teknik finishing kayu serta mengembangkan usaha perkayuan dan mebel dengan desain yang inovatif.

\section{METODE}

Untuk memecahkan permasalahan yang dihadapi oleh kelompok pertukangan di desa Pagerharjo ini maka dipilih beberapa metode pemecahan sebagai berikut.

\section{Metode Ceramah}

Metode ini dipilih untuk menyampaikan teori dan konsep-konsep substansi yang sangat prinsip dan penting yang harus dikuasai oleh para peserta pelatihan teknologi finishing kayu yaitu berupa materi mengenai sifat dasar kayu sebagai bahan mebel, sifat finishing kayu, desain dan inovasi produk mebel, pemasaran produk mebel, bahan finishing kayu serta metode finishing kayu.

\section{Metode Demonstrasi}

Metode ini sangat penting artinya, sebab dalam tahap pelatihan suatu proses kerja akan dapat dengan mudah diikuti oleh peserta apabila keterampilan pokok didemonstrasikan secara nyata oleh pelatih/ instruktur. Dengan demikian, peserta akan dapat mengamati secara sempurna teknik-teknik yang dilakukan oleh pelatih. Materi yang didemonstrasikan oleh pelatih adalah sebagai berikut.

a) Cara mengatur alat semprot untuk keluarnya bahan finishing dan angina.

b) Cara menyemprotkan sanding sealer atau top coat.

\section{Latihan/Praktek}

Metode ini bertujuan untuk memberi bekal keterampilan yang optimal bagi para peserta pelatihan. Dalam metode ini, peserta melakukan sendiri atau mempraktekkan dengan cara menirukan sesuai dengan demonstrasi yang dilakukan oleh pelatih yang memang telah berhasil. Dalam latihan kadang-kadang untuk satu tahap sering diulang-ulang sehingga mendapatkan hasil yang optimal. Untuk mendapatkan hasil keterampilan yang tinggi maka peserta harus mengaplikasikan teknik finishing dengan dua metode yaitu metode kuas dan semprot. 


\section{Evaluasi pasca pelatihan}

Setelah dilakukan pelatihan teknologi finishing kayu, selanjutnya dilakukan evaluasi terhadap hasil pelatihan yang meliputi pengisian kuisioner tentang kegiatan pelatihan finishing kayu serta pendampingan kepada kelompok pertukangan agar dapat konsisten menghasilkan produk kayu sampai tahap finishing. Evaluasi hasil pelatihan ini juga menjadi suatu metode untuk mengukur tingkat keberhasilan pelatihan teknologi finishing kayu yang diberikan kepada kelompok pertukangan yang ada di Desa Pagerharjo, Kecamatan Samigaluh, Kabupaten Kulon Progo, D.I. Yogyakarta.

\section{HASIL DAN PEMBAHASAN}

Kegiatan pelatihan dengan judul "Program Kemitraan Masyarakat Kelompok Pertukangan Desa Pagerharjo, Kecamatan Samigauh, Kabupaten Kulon Progo, D.I. Yogyakarta" dilakukan selama 2 hari di 2 lokasi yaitu hari pertama di Balai Desa Pagerharjo, Kecamatan Samigaluh Kabupaten Kulon Progo dan hari kedua dilaksanakan di bengkel kayu milik salah satu kelompok pertukangan kayu yang juga terletak di Desa Pagerharjo, Kecamatan Samigaluh Kabupaten Kulon Progo. Kegiatan pelatihan ini bekerjasama antara dengan PT Propan Raya ICC Yogyakarta. Narasumber yang memberikan materi dalam kegiatan pelatihan ini berasal dari Program Studi Pengelolaan Hutan Sekolah Vokasi Universitas Gadjah Mada, Fakultas Kehutanan Universitas Gadjah Mada, Asosiasi Pengusaha Mebel Indonesia (ASMINDO) dan PT. Propan Raya ICC Yogyakarta. Pelatihan ini berlangsung selama dua hari yang dijelaskan secara rinci sebagai berikut:

\section{a. Pelatihan hari pertama}

Kegiatan pelatihan pada hari pertama berisi tentang penyampaian materi yang berkaitan tentang teknologi finishing kayu. Secara lebih rinci akan dijelaskan sebagai berikut:

- Materi 1 oleh Dr. Tomy Listyanto, S.Hut., M.Env.Sc. dari Fakultas Kehutanan UGM menjelaskan tentang sifat dasar kayu sebagai bahan pembuatan mebel dan 
furnitur. Pada sesi ini para peserta diharapkan dapat mengetahui jenis-jenis kayu yang mudah diolah menjadi produk mebel dengan keunggulan masing-masing.

- Materi 2 oleh Dr. Navis Rofi'i, S.Hut., M.Sc. dari Fakultas Kehutanan UGM menjelaskan tentang sifat dan pengujian finishing kayu. Pada sesi ini para peserta diharapkan mengetahui tentang sifat finishing kayu yang baik dan mengerti caracara pengujiannya.

- Materi 3 oleh Agus Ngadianto, S.Hut., M.Sc. dari Program Studi Pengelolaan Hutan Sekolah Vokasi UGM yang menjelaskan tentang desain dan inovasi produk mebel. Dengan sesi ini, para peserta diharapkan dapat membuat mebel dan kerajinan kayu dengan desain yang inovatif sehingga dapat menarik minat konsumen.

- Materi 4 oleh Rumekso Setyadi dari perwakilan Asosiasi Pengusaha Mebel Indonesia (ASMINDO) dan selaku pemilik CV. Industri Classica Variasi menjelaskan tentang pemasaran produk mebel dengan sistem teknologi informasi. Pada sesi ini, peserta diharapkan dapat memperluas jaringan pemasarannya secara online agar dapat meningkatkan nilai penjualan produk mebel.

- Materi 5 oleh Petrus Risa Kurnianto dari PT. Propan Raya ICC Yogyakarta yang menjelaskan tentang jenis dan sifat bahan finishing serta cara aplikasinya pada produk mebel. Pada sesi ini para peserta diharapkan mengetahui jenis-jenis bahan finishing yang cocok bagi kayu dan cara mengapikasikannya pada produk mebel.

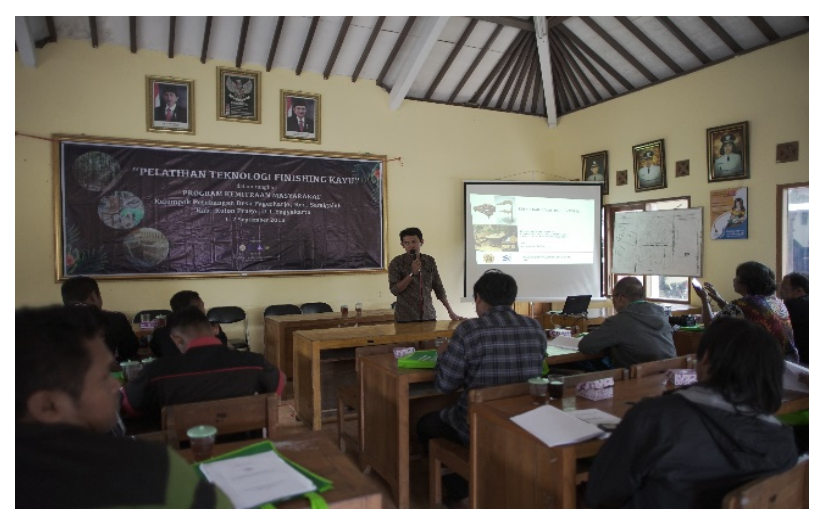

Gambar 1. Penyampaian materi pelatihan teknologi finishing kayu 


\section{b. Pelatihan hari kedua}

Pelatihan hari kedua berisi tentang praktek finishing kayu dengan bahan finishing berbasis air, minyak dan kombinasi keduanya. Tujuan penggunaan bahan finishing berbasis air adalah untuk mengenalkan kepada peserta pelatihan mengenai bahan finishing yang ramah lingkungan serta untuk diterapkan pada produk interior. Sementara itu, penggunaan bahan finishing berbahan minyak serta kombinasi antara keduanya bertujuan untuk mengetahui perbedaan hasil finishing pada kayu. Pada pelatihan hari kedua ini, para peserta diajarkan tahapan aplikasi finishing kayu mulai dari menyiapkan bahan dasar sampai tahap finising selesai secara total yang meliputi tahapan pengamplasan kayu, pemberian wood filler atau dempul, pemberian warna dasar, pelapisan dengan sanding sealer dan pelapisan akhir top coat. Pada praktek finishing kayu ini, para peserta di minta untuk melakukan teknik finishing kayu dengan dua metode yaitu metode konvensional menggunakan kuas dan metode finishing menggunakan semprotan. Sebelumnya telah didemontrasikan mengenai aplikasi finishing kayu oleh instruktur pelatihan.

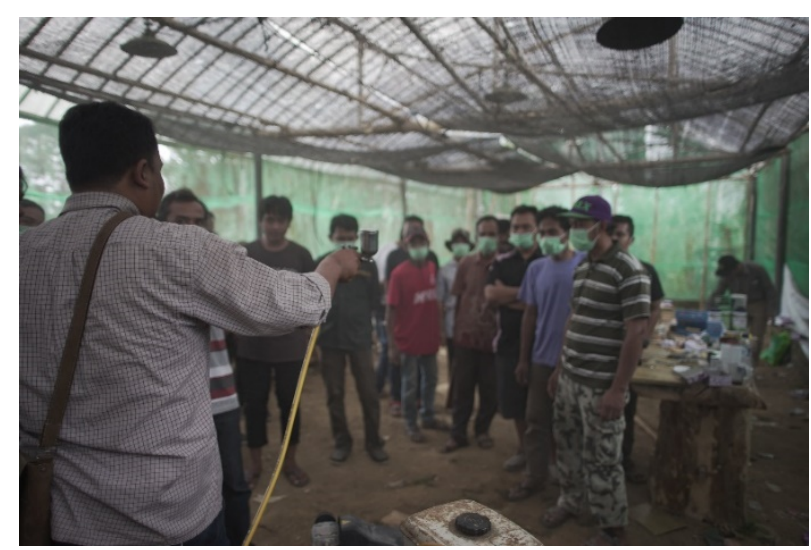

Gambar 2. Demontrasi teknik finishing kayu oleh instruktur 


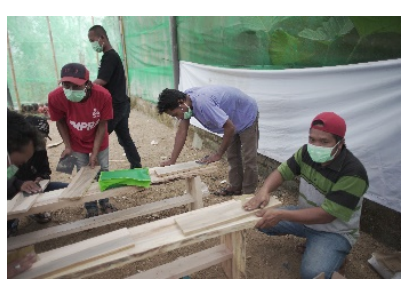

1.Pengamplasan

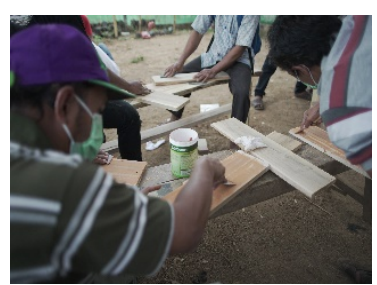

2. Wood filler

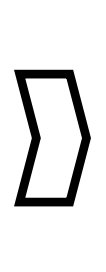

ए5.

3. Pewarnaan

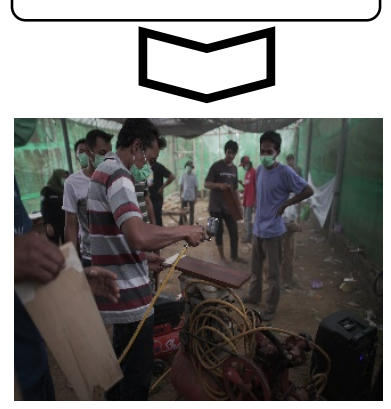

4. Sanding sealer

\section{Top coat}
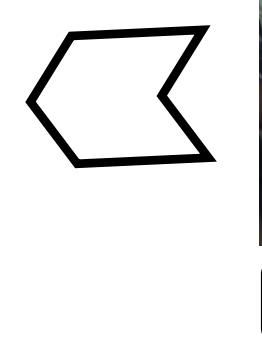

Gambar 3. Proses tahapan finishing kayu

Teknik finishing kayu dengan metode kuas atau penguasan maupun metode penyemprotan sangat mudah dilakukan yaitu hanya dengan menguaskan atau menyemprotkan bahan finishing kekayu secara langsung. Hal yang perlu di perhatikan adalah kerataan bahan finishing yang di kuaskan atau di semprotkan kekayu. Aplikasi penguasan atau penyemprotan yang terlalu tebal akan menimbulkan cacat finishing berupa banyaknya gelembung udara pada kayu yang di finishing (Susanto, 2011).

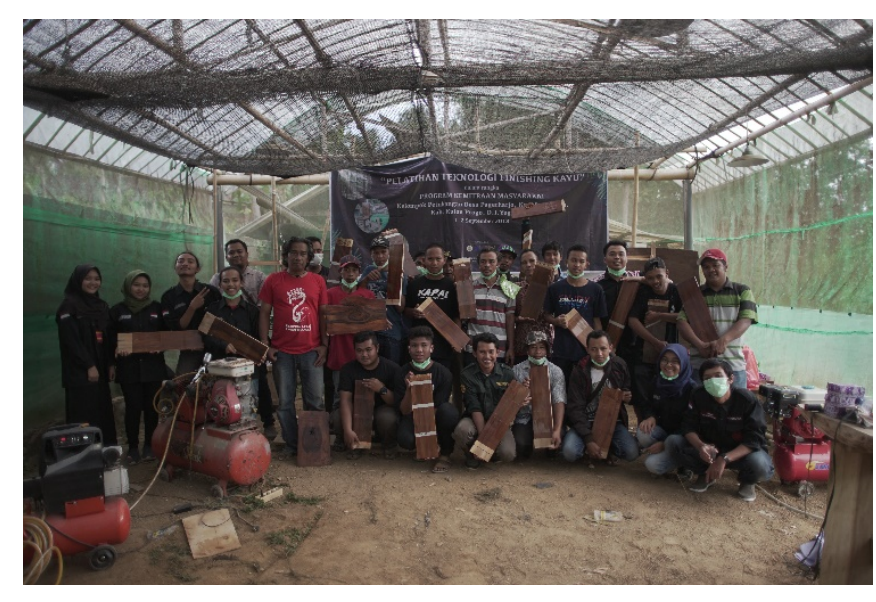

Gambar 4. Peserta pelatihan teknologi finishing kayu 
Tabel 1. Hasil evaluasi pelatihan teknologi finishing kayu

\begin{tabular}{|c|c|c|c|c|}
\hline \multirow{2}{*}{ No } & \multirow{2}{*}{ Poin Evaluasi } & \multicolumn{3}{|c|}{ Jawaban (\%) } \\
\hline & & Ya & Tidak & Tidak Tahu \\
\hline 1 & $\begin{array}{l}\text { Teknologi finishing kayu ini bermanfaat bagi kelompok } \\
\text { pertukangan }\end{array}$ & 100 & 0 & 0 \\
\hline 2 & Materi pelatihan yang diberikan sesuai dengan yang dibutuhkan & 100 & 0 & 0 \\
\hline 3 & $\begin{array}{l}\text { Metode pelatihan yang digunakan sesuai dengan jenis pelatihan } \\
\text { yang dibutuhkan }\end{array}$ & 95 & 0 & 5 \\
\hline 4 & $\begin{array}{l}\text { Kemampuan narasumber dan instruktur pelatihan dalam } \\
\text { memberikan pelatihan sudah sesuai harapan }\end{array}$ & 95 & 0 & 5 \\
\hline 5 & Sarana dan prasarana pelatihan yang diterapkan sudah efektif? & 27,5 & 12,5 & 60 \\
\hline 6 & Antusiasme peserta pelatihan yang ikut dalam pelatihan tinggi & 95 & 0 & 5 \\
\hline 7 & $\begin{array}{lllll}\begin{array}{l}\text { Sebelumnya sudah mengenal tentang finishing produk } \\
\text { perkayuan }\end{array} & & & \\
\end{array}$ & 40 & 40 & 20 \\
\hline 8 & $\begin{array}{l}\text { Finshing kayu dengan cara kuas merupakan metode yang paling } \\
\text { mudah untuk diterapkan }\end{array}$ & 80 & 5 & 15 \\
\hline 10 & $\begin{array}{l}\text { Tahapan finishing penting diketahui untuk mendapatkan hasil } \\
\text { finishing dengan kualitas terbaik }\end{array}$ & 92,5 & 0 & 7,5 \\
\hline 11 & $\begin{array}{l}\text { Finishing kayu dengan cara semprot merupakan metode yang } \\
\text { memberikan hasil paling baik }\end{array}$ & 32,5 & 7,5 & 60 \\
\hline 12 & Finishing akan menambah nilai jual pada produk perkayuan & 100 & 0 & 0 \\
\hline 13 & $\begin{array}{l}\text { Setelah mengikuti pelatihan finishing akan muncul ide baru } \\
\text { dalam membuat produk perkayuan }\end{array}$ & 95 & 0 & 5 \\
\hline
\end{tabular}

Peserta pelatihan teknologi kayu ini berjumlah 40 orang yang tergabung dalam dua kelompok pertukangan yaitu Muda Taruna Makmur dan Mitra Mandiri. Kedua kelompok ini berdomisili di Desa Pagerharjo. Sebagian besar anggota kelompok pertukangan ini merupakan pemuda desa dengan kisaran umur dibawah 31 tahun (Gambar 5). Tabel 1. menunjukkan hasil evaluasi setelah kegiatan pelatihan teknologi finishing. Hasil yang diperoleh dari evaluasi tersebut adalah seluruh peserta pelatihan berpendapat bahwa kegiatan pelathan finishing kayu sangat penting dalam meningkatkan keahlian mereka dimana sebelumnya tidak sampai setengah dari jumlah peserta yang mengetahui tentang teknologi finishing kayu. 


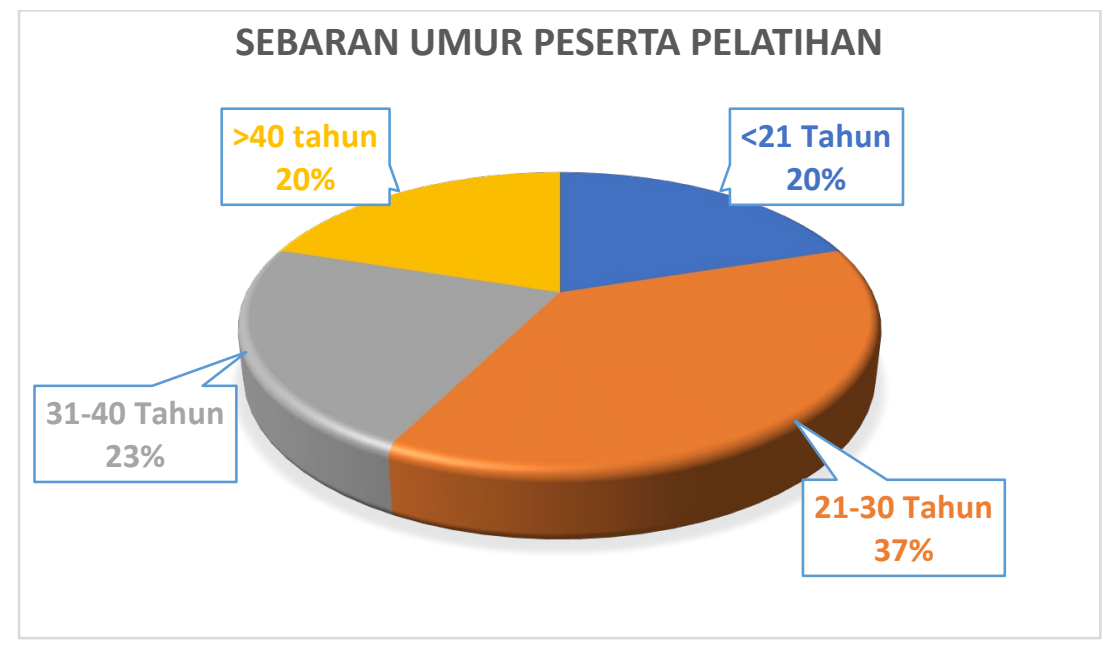

Gambar 5. Sebaran umur peserta pelatihan teknologi finishing kayu

\section{KESIMPULAN}

1. Pengolahan kayu dari hutan rakyat menjadi produk perkayuan di Kabupaten Kulon Progo telah banyak dilakukan tetapi masih belum disertai dengan teknologi pengerjaan akhir (finishing) yang tepat.

2. Kelompok pertukangan dan pengrajin kayu antusias menerima ilmu pengetahuan tentang teknologi finishing kayu agar dapat menghasilkan produk kayu yang memiliki kualitas yang baik dan bernilai jual tinggi.

3. Kelompok pertukangan kayu di Desa Pagerharjo telah dapat melakukan tahapan-tahapan teknik finishing kayu secara tepat dan mandiri dengan menerapkan dua metode sederhana yaitu cara penguasan dan cara penyemprotan.

4. Praktek finishing kayu yang dilaksanakan menggunakan bahan finishing berbasis air, minyak dan kombinasi keduanya. Penggunaan bahan finishing berbasis air lebih diutamakan untuk mengenalkan kepada masyarakat mengenai bahan finishing yang ramah lingkungan serta dapat diterapkan pada produk kayu untuk interior. 


\section{DAFTAR PUSTAKA}

Badan Pusat Statistik. 2015. Kecamatan Samigaluh Dalam Angka 2015. PT. Pohon Cahaya. Yogyakarta.

Kasmudjo. 2010. Teknologi Hasil Hutan (Suatau Pengantar). Cakrawala Media. Yogyakarta.

Purnama, Fx.S. 2009. Teknik Finishing Mebel. Dahara Prize. Semarang.

Sudaryanto, D, 2005. Wood Finishing Industry. General Lecture pada Fakultas Kehutanan UGM.

Susanto, 2011. Finishing untuk pemula, www.finishinguntukpemula.blogspot.com 